\title{
Study of learner Behavior and Learning Styles on the Adaptive Learning Management System Manhali: Results and Analysis According to Gender and Academic Performance
}

\author{
Ismail El Haddioui ${ }^{1}$, Mohamed Khaldi ${ }^{2}$ \\ ${ }^{1}$ RITM lab, Hassan II University, Superior School of Technology, Casablanca, Morocco. \\ ${ }^{2}$ LIROSA lab, Abdelmalek Essaadi University, Faculty of Sciences, Tetouan, Morocco. \\ * Corresponding author. Tel.: +212 660725 121; email: ismail.elhaddioui@gmail.com \\ Manuscript submitted January 10, 2017; accepted March 8, 2017. \\ doi: 10.17706/jsw.12.4.212-226
}

\begin{abstract}
This paper presents the detailed results of the study that we performed on our adaptive Learning Management System Manhali. This study was addressed to first year university students in Computer Engineering. The experiment was in the form of an online course intended to analyze and evaluate learner behavior on the e-learning platform and to identify their learning styles according to two learning styles theories: Kolb's theory and Felder's theory. The main objective was to study two important relationships in e-learning systems: The relationship between the behavior of a learner and their academic performance, and the relationship between the gender of the learner and their learning style.
\end{abstract}

Keywords: E-Learning; learner modeling; learner profile; learning style; learner behavior; gender differences.

\section{Introduction}

In e-learning, teacher may lose the large human interaction that exists in a classic classroom with all information that can be obtained from this situation as the estimation of differences in learning styles, approaches to learn and levels of intellectual development of learners. In this case, and to improve the performance of the e-learning, we need to take into account some learner preferences that teachers use in a classic classroom to improve the learning situation, like cognitive development, motivation, learning style, behavior and level of attention.

Manhali: our adaptive Learning Management provides a measure of some criteria to evaluate learners' behavior and learning style. That may allow us in the future to adapt the educational content to the current needs of each learner by generating new customized learning situations.

This experiment was in the form of training about web development in PHP language. The course consisted of 8 chapters with concrete application, exercises, assignments and self-assessment. The training took place for a month on Manhali system.

\subsection{Objectives of the Experiment}

This experiment had two objectives:

The first objective was to analyze and evaluate learner behavior using some indicators of interaction between the learner and the system, and also the indicators of the use of educational tools on the platform [1].

The second objective was to determine the learning style of learners using two different methods: 
- Felder's Learning Styles Questionnaire: "Index of Learning Styles of Felder and Silverman" [2].

- Using indicators of observed behavior on the platform to classify learners by Kolb's model of learning style: "Learning Styles Theory of Kolb" [3].

\subsection{Data Collection}

Data collection was performed by the system on three levels:

- Learner's traces of interaction with the system and the use of educational tools on the platform. These traces are used to analyze and evaluate the behavior, as well as for the detection of learning style according to Kolb's theory.

- Learner's marks that are added manually by trainers (homework assignment) or calculated by the system (self-assessment tests)

- A questionnaire to determine the learning style according to Felder's theory.

\section{Methods}

\subsection{Sample of the Population}

\subsubsection{The sample}

The sample consists of 118 students; the behavior and learning style analysis included only the 89 students who accessed the platform, the other 29 students have never used the educational tools of the platform. The access data to the platform are detailed in the following table:

Table 1. Statistics of Learners' Connections to the Platform

\begin{tabular}{|c|c|c|}
\hline Connections to the platform & Number of learners & Percentage \\
\hline Never logged in & 29 & $24.58 \%$ \\
\hline Logged in once & 9 & $7.63 \%$ \\
\hline Logged in more than once & 80 & $67.80 \%$ \\
\hline Total & 118 & $100.00 \%$ \\
\hline
\end{tabular}

\section{Connections to the platform}

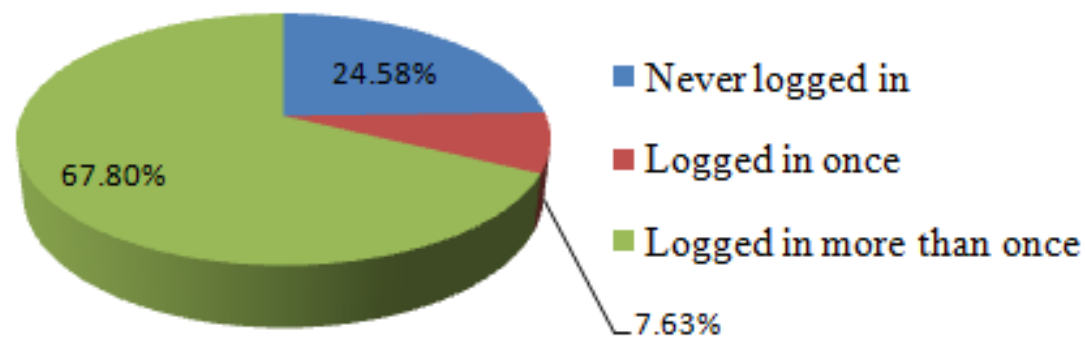

Fig. 1. Graph of connections to the platform.

\subsubsection{Distribution of the sample}

In this study, we used the gender as a variable for the distribution of the sample. Other variables are almost identical for all participants. The age of participants is not very diverse between 18 and 22 years, occupation and region are also the same.

In terms of gender, our sample of 118 students includes 57 women and 61 men, which represents $48.31 \%$ and $51.69 \%$ of the sample. 


\section{Gender distribution}

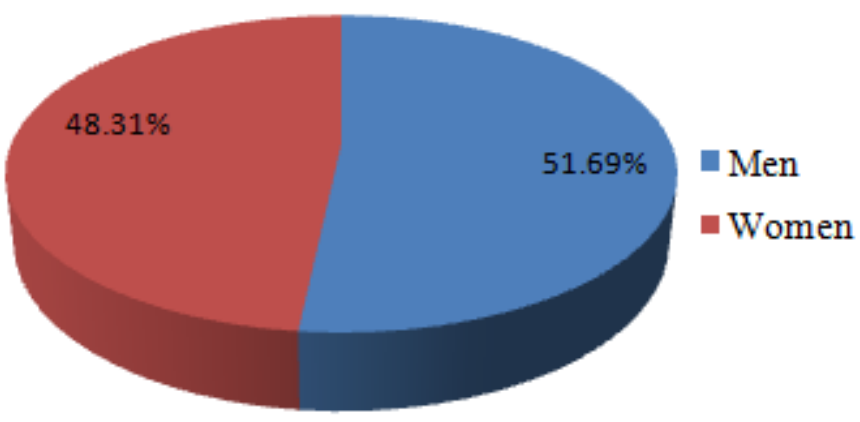

Fig. 2. Distribution of the sample by gender.

\subsection{Behavior Analysis}

We studied learners' behavior by our behavioral analysis method using seven indicators collected from traces of interaction between the learner and the system and also the traces of the use of educational tools on the platform. The seven indicators are:

I1. Number of connections to the platform;

I2. Number of visited pages;

I3. Total time spent on the platform;

I4. Number of tries in self-evaluation;

I5. Number of achieved homework assignments;

I6. Number of messages;

17. Number of comments on course and article section.

For each indicator, we calculate the percentage of activities performed by a learner on the total number of activities performed by all active learners of their class. An active learner is a learner who accessed the platform at least once.

To evaluate the behavior and detect learners' behavioral changes, the system calculates a final score to compare these changes in a range of dates (weekly, monthly ...). The final score is the average of all confirmed marks obtained by a student. A mark is confirmed only when the activity is already performed by at least one-tenth $(1 / 10)$ of all active learners. $1 / 10$ is the default value to take into consideration only the activities that involve at least $10 \%$ of the class, however, this value can be changed by the administrator of the platform, it's depends on the type of activities and the motivation of the group.

$$
\text { Learner score }=\sum \text { Confirmed marks } / \text { Number of confirmed indicators }
$$

Then, the system arranges the learners using 5 grades (A, B, C, D and E) according to the final behavior score to allow teachers to customize the educational content for each grade. The grade is determined by the following "A" coefficient:

$$
A=\text { Learner score } * \text { Number of active learners } / 100
$$

The behavior grade is assigned according to the following table:

Table 1. Behavior Grade According to "A" Coefficient

\begin{tabular}{|l|l|}
\hline \multicolumn{1}{|c|}{ "A" Coefficient } & \multicolumn{1}{c|}{ Grade } \\
\hline Lower than 0.5 & E \\
\hline Between 0.5 and 1 & D \\
\hline Between 1 and 2 & C \\
\hline
\end{tabular}




\begin{tabular}{|l|l|}
\hline Between 2 and 4 & B \\
\hline Higher than 4 & A \\
\hline
\end{tabular}

\subsection{Learning Style Analysis}

Learning style is one of the individual differences that play an important role in learning. Learning style designates everything that is characteristic to an individual when she/he is learning, i.e. a specific manner of approaching a learning task, the learning strategies activated in order to fulfill the task [4]. There have been given several definitions:

- A predisposition on the part of some students to adopt a particular learning strategy regardless of the specific demands of the learning task [5];

- The composite of characteristic cognitive, affective, and psychological factors that serve as relatively stable indicators of how a learner perceives, interacts with, and responds to the learning environment [6];

- An individual's preferred approach to organizing and presenting information [7];

- The way in which learners perceive, process, store and recall attempts of learning [8];

- Distinctive behaviors which serve as indicators of how a person learns from and adapts to his environment, and provide clues as to how a person's mind operates [9];

- A gestalt combining internal and external operations derived from the individual's neurobiology, personality and development, and reflected in learner behavior [10].

As we can see, learning style has been attributed several connotations in the literature. That is why there are many models in this research field [11]:

Learning Styles Theory of Kolb (1985);

Index of Learning Styles of Felder and Silverman (1988);

Learning Styles of Honey and Mumford (1992);

Student Learning Style Scales of Grasha (1996);

Multiple Intelligences of Gardner (1999);

Auditory Visual Tactile Learning Styles of Sarasin (1998).

In this study, we will compare two main models of measurement learning style: Kolb's model and Felder's model.

Our choice is justified by two reasons: first, because these two models of face-to-face learning can be used in e-learning, Felder's questionnaire can be easily integrated into an e-learning platform, and regarding the Kolb model, we found that its dimensions are very compatible with the behavioral indicators that we use in our behavioral analysis system. The second reason is the coherence between these two models. Felder and Kolb models have two common dimensions that allow comparison of learning style analysis results, the first dimension is the Active/Reflective style, and the second is the Sensing/Intuitive style according to Felder, that Kolb calls it Concrete/Abstract style.

\section{Results}

\subsection{Behavior Results}

Here are some results of the performed behavior study:

Table 2. Results of the Behavior Study

\begin{tabular}{|c|c|c|c|c|c|c|c|c|c|c|}
\hline $\begin{array}{c}\text { Learner } \\
\text { Id }\end{array}$ & I1 & I2 & I3 & I4 & I5 & I6 & I7 & Final score & $\begin{array}{c}\text { "A" } \\
\text { Coefficient }\end{array}$ & Grade \\
\hline 1 & $0,11 \%$ & $0,14 \%$ & $0,03 \%$ & $0,00 \%$ & $0,00 \%$ & $0,00 \%$ & $0,00 \%$ & $0,04 \%$ & 0,03 & $\mathrm{E}$ \\
\hline
\end{tabular}




\begin{tabular}{|c|c|c|c|c|c|c|c|c|c|c|}
\hline 2 & $2,74 \%$ & $2,43 \%$ & $1,44 \%$ & $2,73 \%$ & $1,79 \%$ & $2,75 \%$ & $0,00 \%$ & $1,98 \%$ & 1,77 & $\mathrm{C}$ \\
\hline 3 & $0,00 \%$ & $0,00 \%$ & $0,00 \%$ & $0,00 \%$ & $0,00 \%$ & $0,00 \%$ & $0,00 \%$ & $0,00 \%$ & 0,00 & Undefined \\
\hline 4 & $0,32 \%$ & $0,32 \%$ & $0,67 \%$ & $0,76 \%$ & $0,00 \%$ & $0,92 \%$ & $2,22 \%$ & $0,74 \%$ & 0,66 & $\mathrm{D}$ \\
\hline 5 & $6,33 \%$ & $1,57 \%$ & $0,60 \%$ & $1,29 \%$ & $1,79 \%$ & $1,72 \%$ & $2,22 \%$ & $2,22 \%$ & 1,97 & $\mathrm{C}$ \\
\hline 6 & $4,11 \%$ & $2,76 \%$ & $5,13 \%$ & $2,28 \%$ & $1,79 \%$ & $2,75 \%$ & $0,00 \%$ & $2,69 \%$ & 2,39 & $\mathrm{~B}$ \\
\hline
\end{tabular}

\subsubsection{Overall results}

The statistics of behavior grade were as follows:

Table 3. Statistics of Behavior Grade

\begin{tabular}{|l|r|r|}
\hline \multicolumn{1}{|c|}{ Behavior grade } & Number of learners & \multicolumn{1}{c|}{ Percentage } \\
\hline "A" Grade & 0 & $0.00 \%$ \\
\hline "B" Grade & 10 & $8.47 \%$ \\
\hline "C" Grade & 30 & $25.42 \%$ \\
\hline "D" Grade & 19 & $16.10 \%$ \\
\hline "E" Grade & 30 & $25.42 \%$ \\
\hline Undefined & 29 & $24.58 \%$ \\
\hline Total & 118 & $100.00 \%$ \\
\hline
\end{tabular}

\section{Behavior grade}

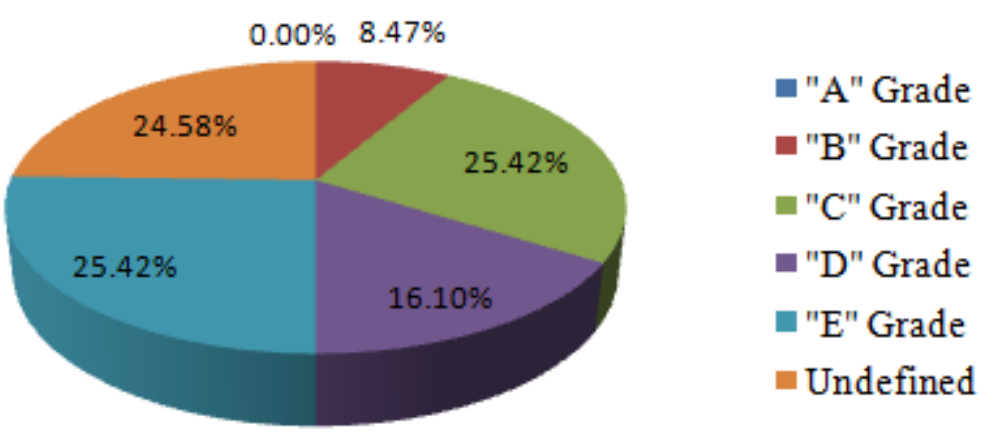

Fig. 3. Graph of behavior grades.

The "undefined" group contains the 29 learners who have never accessed the platform. Besides this group, the most frequent grade is " $C$ " whose "A" coefficient is between 1 and 2 , and " $E$ " grade whose " $A$ " coefficient is lower than 0.5 .

\subsubsection{Behavior results distribution by gender}

The distribution of learners' behavior by gender showed the following results:

Table 4. Behavior Grades Distribution by Gender

\begin{tabular}{|l|r|r|r|r|r|r|}
\cline { 2 - 6 } \multicolumn{1}{c|}{} & \multicolumn{2}{c|}{ Men } & \multicolumn{2}{c|}{ Women } & \multicolumn{2}{c|}{ Total } \\
\cline { 2 - 7 } \multicolumn{1}{c|}{} & \multicolumn{1}{c|}{ Number } & Percentage & Number & Percentage & Number & Percentage \\
\hline "A" Grade & 0 & $0.00 \%$ & 0 & $0.00 \%$ & 0 & $0.00 \%$ \\
\hline
\end{tabular}




\begin{tabular}{|l|r|r|r|r|r|r|}
\hline “B” Grade & 4 & $10.53 \%$ & 6 & $11.76 \%$ & 10 & $11.24 \%$ \\
\hline “C” Grade & 10 & $26.32 \%$ & 20 & $39.22 \%$ & 30 & $33.71 \%$ \\
\hline “D” Grade & 10 & $26.32 \%$ & 9 & $17.65 \%$ & 19 & $21.35 \%$ \\
\hline “E” Grade & 14 & $36.84 \%$ & 16 & $31.37 \%$ & 30 & $33.71 \%$ \\
\hline
\end{tabular}

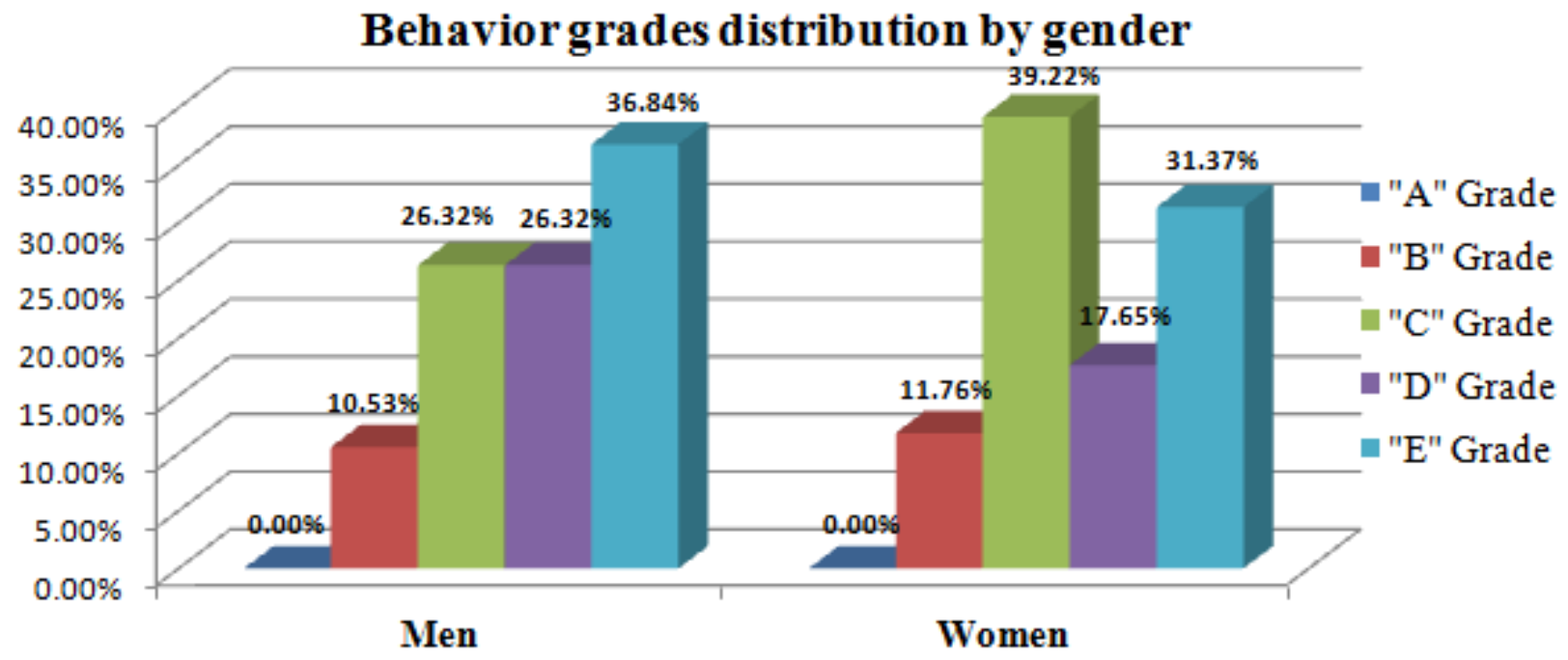

Fig. 4. Graph of behavior grades distribution by gender.

It was found that women received higher results than men in relation to the observed behavior. Regarding the " $\mathrm{B}$ " grade, the percentage of women is higher than men, $11 \%$ vs. $10 \%$, as well as for " $\mathrm{C}$ " grade, which marked a larger gap between them, $39 \%$ for women vs. only $26 \%$ for men. For the " $D$ " and "E" grades, men scored a higher percentage than women.

\subsection{Learning Style Results}

The detection of learning style was done according to Kolb's theory and Felder's theory. Kolb's learning styles are detected from our behavioral indicators collected on the platform, and Felder's learning styles are calculated from the results of a questionnaire.

\subsubsection{Kolb's learning styles}

Based on the various modes of learning, Kolb identifies four Learning Styles [3]:

LS1. Accommodating Style (Active, Concrete): Feel and do.

LS2. Converging Style (Abstract, Active): Think and do.

LS3. Assimilating Style (Reflective, Abstract): Think and watch.

LS4. Diverging Style (Concrete, Reflective): Feel and watch.

We classified the four learning styles of Kolb into only two categories [12]:

- The active experimenter (accommodating/converging style): This category includes students who prefer handling, task execution and activities implementation.

- The reflective observer (assimilating/diverging style): observers and conceptualizers who prefer to work on ideas and theories.

\section{- Overall results}

The determination of Kolb's learning styles showed the following results: 
Table 5. Kolb's Learning Styles

\begin{tabular}{|l|r|r|}
\hline \multicolumn{1}{|c|}{ Learning style } & $\begin{array}{c}\text { Number } \\
\text { of } \\
\text { learners }\end{array}$ & Percentage \\
\hline Accommodating/Converging Style (LS1 and LS2) & 49 & $41.53 \%$ \\
\hline Assimilating/Diverging Style (LS3 and LS4) & 40 & $33.90 \%$ \\
\hline Undefined & 29 & $24.58 \%$ \\
\hline Total & 118 & $100.00 \%$ \\
\hline
\end{tabular}

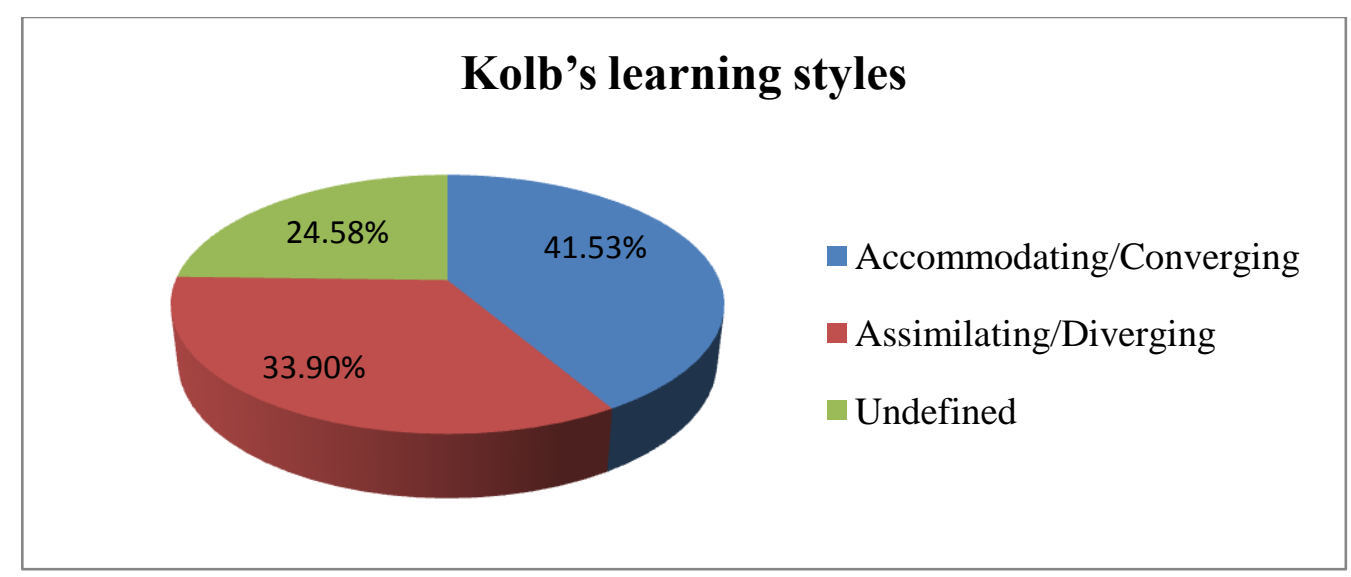

Fig. 5. Graph of Kolb's learning styles.

\section{Kolb's learning styles distribution by gender}

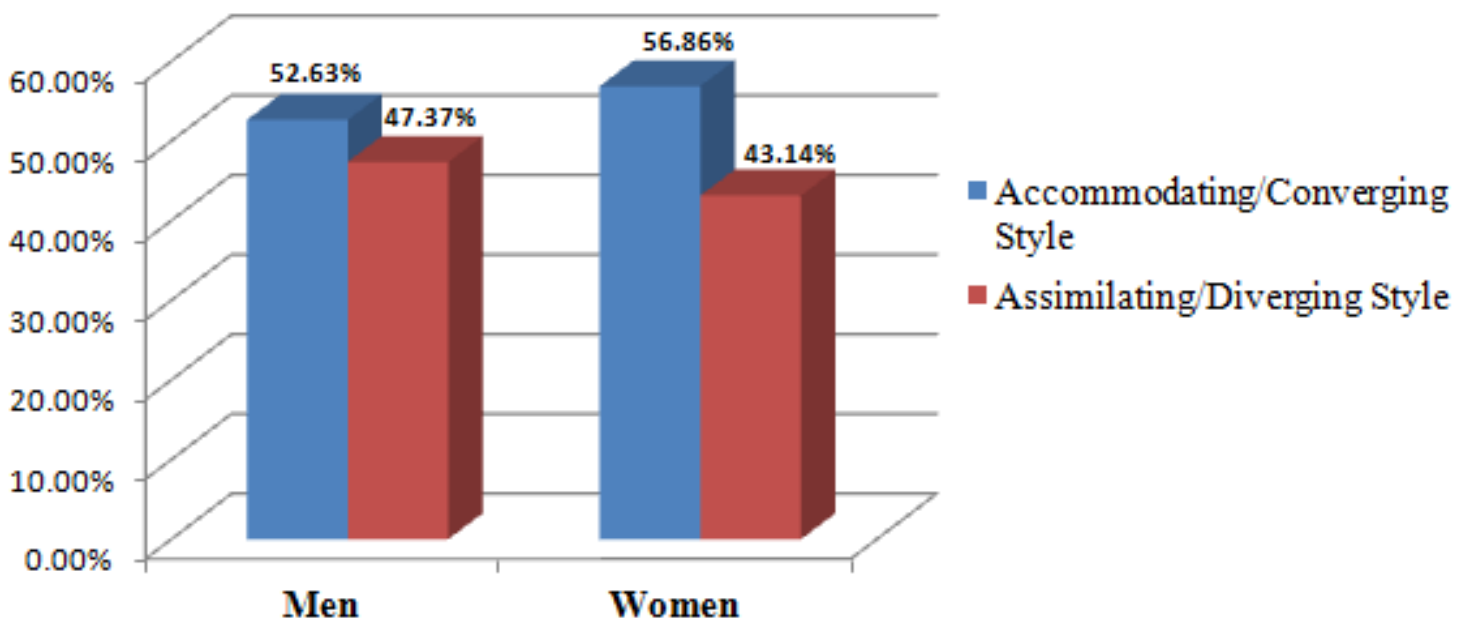

Fig. 6. Graph of Kolb's learning styles distribution by gender.

This figure shows that the "Accommodating/Converging" style is the learning style in which the percentage is the highest at $41 \%$; this style includes learners who prefer handling and task execution. The learners who have the "Assimilating/Diverging" style -observers and conceptualizers who prefer theory, represent only $33 \%$ of our sample.

- Distribution of Kolb's learning styles results by gender

Let us now examine the distribution of previous results by gender: 
Table 6. Kolb’s Learning Styles Distribution by Gender

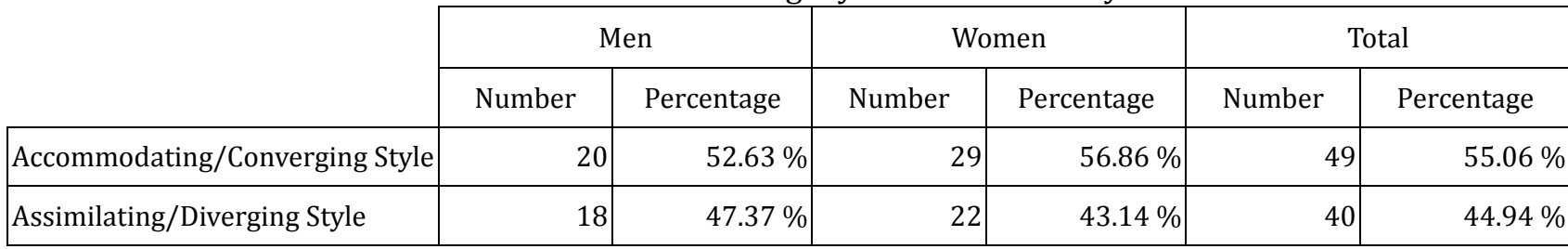

This figure shows that the percentage of women who have an "Accommodating/Converging" style is higher than men by $56 \%$ against $52 \%$. For the "Assimilating/Diverging" style, the percentage of men is higher, measuring $47 \%$ against $43 \%$ for women.

\subsubsection{Felder's learning styles}

Felder proposes a model composed of four dimensions to define the student's learning style [13]:

D1. Reflection: How does the student prefer to process information: "actively" through engagement in physical activity or discussion, or "reflectively" through introspection?

D2. Reasoning: What type of information does the student preferentially perceive: "sensory" sights, sounds, physical sensations, or "intuitive" memories, ideas, and insights?

D3. Sensory: Through which modality is sensory information most effectively perceived: "visual" pictures, diagrams, graphs, demonstrations, or "verbal" sounds -written and spoken words and formulas?

D4. Progression: How does the student progress toward understanding: "sequentially" -in a logical progression of small incremental steps, or "globally" in large jumps, holistically?

\section{- 3.2.2.1. Overall results}

The ILS questionnaire [14] provided the following results:

Table 7. Felder's Learning Styles

\begin{tabular}{|l|l|r|r|}
\hline \multirow{4}{*}{ Dimension } & Learning style & Number & \multicolumn{1}{|l|}{ Percentage } \\
\hline \multirow{5}{*}{ Reflection } & Active & 33 & $27.97 \%$ \\
\cline { 2 - 4 } & Reflective & 56 & $47.46 \%$ \\
\cline { 2 - 4 } & Undefined & 29 & $24.58 \%$ \\
\hline \multirow{5}{*}{ Sensoning } & Sensing & 48 & $40.68 \%$ \\
\cline { 2 - 4 } & Intuitive & 41 & $34.75 \%$ \\
\cline { 2 - 4 } & Undefined & 29 & $24.58 \%$ \\
\hline \multirow{3}{*}{ Progression } & Visual & 47 & $39.83 \%$ \\
\cline { 2 - 4 } & Verbal & 42 & $35.59 \%$ \\
\cline { 2 - 4 } & Undefined & 29 & $24.58 \%$ \\
\hline & Sequential & 32 & $27.12 \%$ \\
\cline { 2 - 4 } & Global & 57 & $48.31 \%$ \\
\cline { 2 - 4 } & Undefined & 29 & $24.58 \%$ \\
\hline
\end{tabular}

Regarding the reflection dimension, we notice that most learners have the reflective style: $47 \%$ against only $27 \%$ of active learners. That means the majority of our sample prefer activities that require personal effort of analysis. Recall that a reflective learner often prefers to work alone or with one regular partner, however, an active learner tends to like group work. 


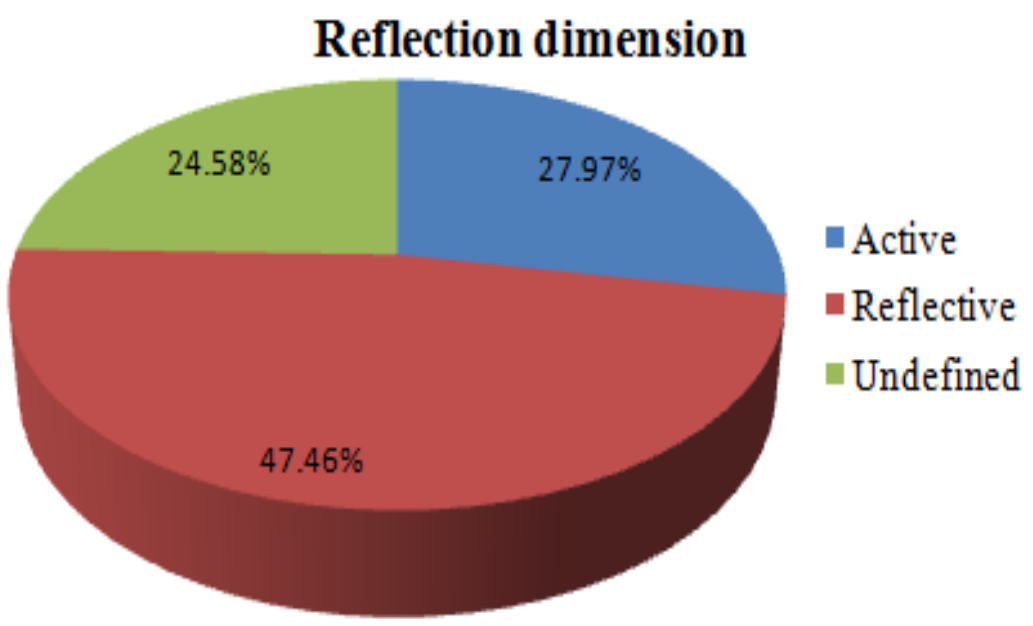

Fig. 7. Felder's learning styles - Reflection dimension.

\section{Reasoning dimension}

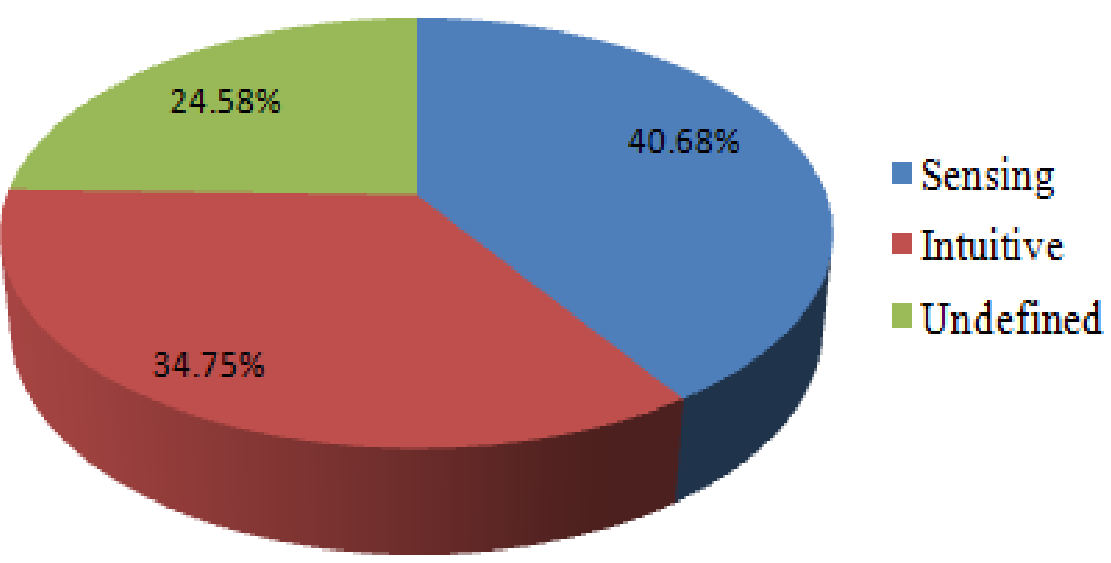

Fig. 8. Felder's learning styles - Reasoning dimension.

\section{Sensory dimension}

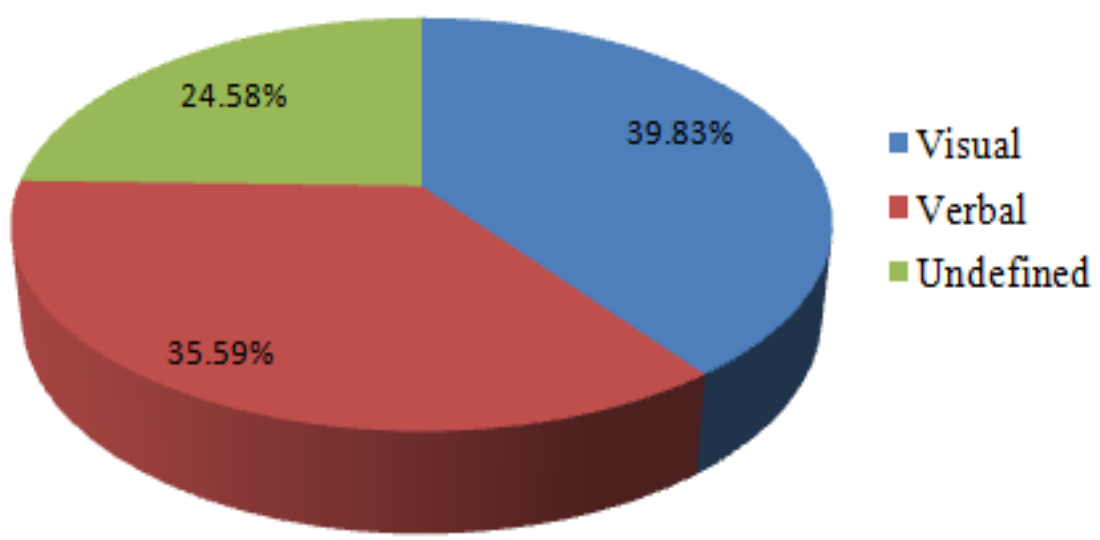

Fig. 9. Felder's learning styles - Sensory dimension.

Concerning the reasoning dimension, the results are not very divergent. The percentage of the sensing style is $40 \%$ against $34 \%$ for the intuitive style. To reiterate, sensing learners engage in concrete reasoning 
and they tend to like learning facts, while intuitive learners prefer abstract reasoning; they like innovation and dislike repetition.

Let us now examine the sensory dimension. The results are very similar between the visual style with $39 \%$ and the verbal style with 35\%. Visual learners remember best what they see -like pictures, diagrams, flow charts, time lines, films, and demonstrations. Verbal learners get more out of words, through either written or spoken explanations.

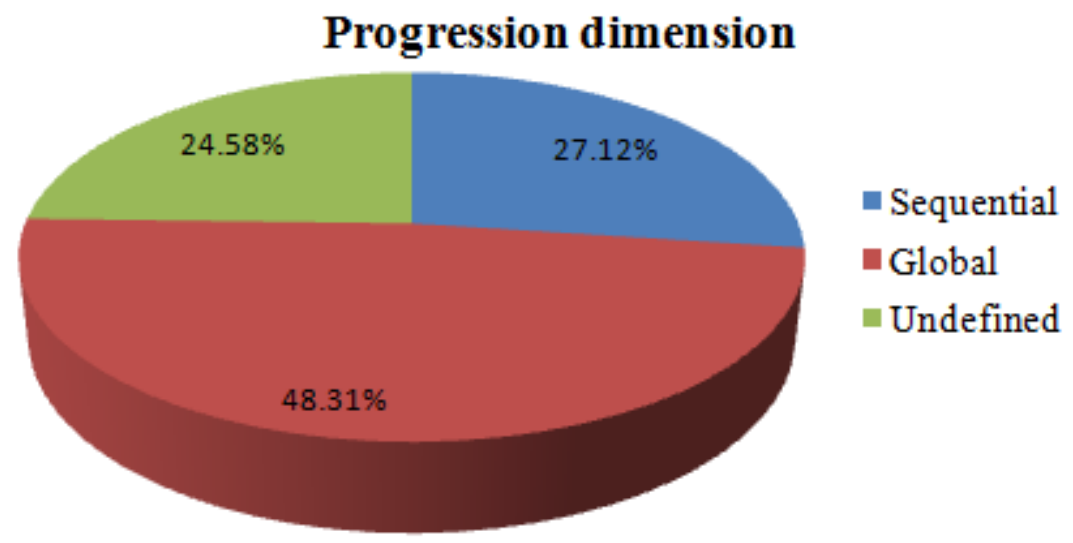

Fig. 10. Felder's learning styles - Progression dimension.

Regarding the progression dimension, it was found that global learners dominate with $48 \%$ against only $27 \%$ sequential learners. Sequential learners tend to gain understanding in linear steps, with each step following logically from the previous one. Global learners tend to learn in large jumps and they may be able to solve complex problems quickly or put things together in novel ways once they have grasped the big picture.

- Distribution of Felder's learning styles results by gender

Let us now examine the distribution of previous results by gender:

- $\quad$ Reflection dimension

Table 8. Reflection Dimension Distribution by Gender

\begin{tabular}{|c|c|c|c|c|c|c|}
\hline & \multicolumn{2}{|c|}{ Men } & \multicolumn{2}{|c|}{ Women } & \multicolumn{2}{|c|}{ Total } \\
\hline & Number & Percentage & Number & Percentage & Number & Percentage \\
\hline Active & 13 & $34.21 \%$ & 20 & $39.22 \%$ & 33 & $37.08 \%$ \\
\hline Reflective & 25 & $65.79 \%$ & 31 & $60.78 \%$ & 56 & $62.92 \%$ \\
\hline
\end{tabular}




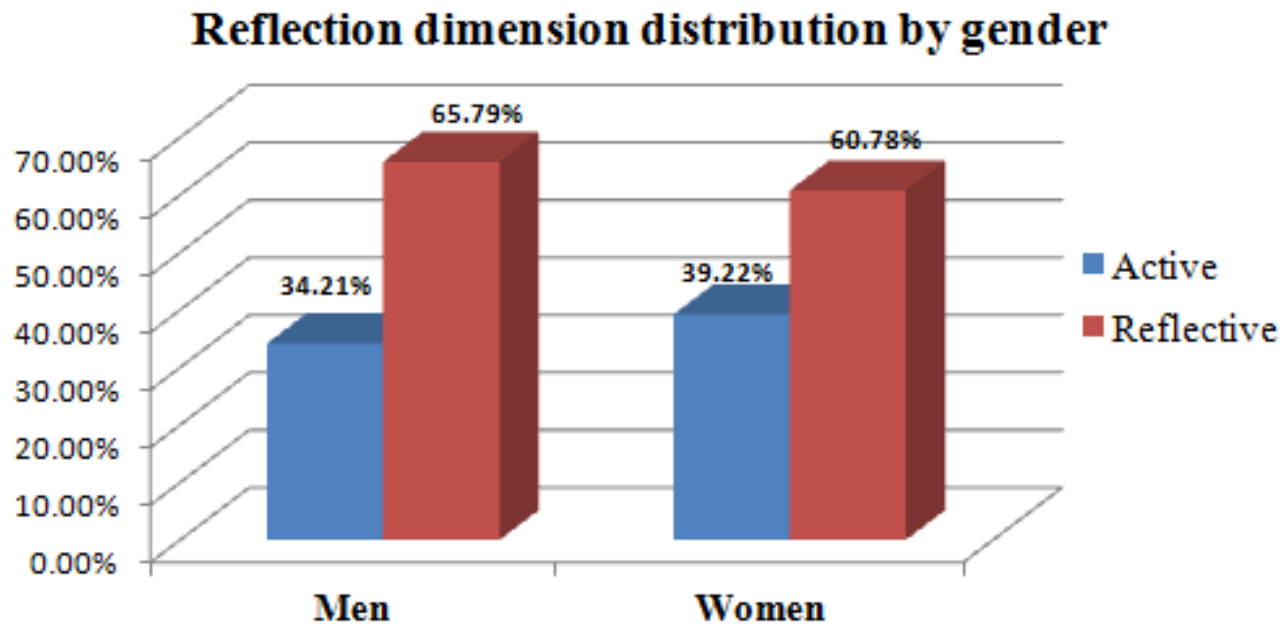

Fig. 11. Graph of reflection dimension distribution by gender.

This figure shows that the percentage of women who have an active style is higher than men (39\% against 34\%). On the other hand, most of the men in our sample gravitate toward the reflective style with $65 \%$ against $60 \%$ for women.

- $\quad$ Reasoning dimension

Table 9. Reasoning Dimension Distribution by Gender

\begin{tabular}{|l|r|r|r|r|r|r|}
\cline { 2 - 7 } \multicolumn{1}{c|}{} & \multicolumn{2}{c|}{ Men } & \multicolumn{2}{c|}{ Women } & \multicolumn{2}{c|}{ Total } \\
\cline { 2 - 7 } \multicolumn{1}{c|}{} & \multicolumn{2}{c|}{ Number } & Percentage & Number & Percentage & \multicolumn{2}{c|}{ Number } & \multicolumn{1}{c|}{ Percentage } \\
\hline Sensing & 20 & $52.63 \%$ & 28 & $54.90 \%$ & 48 & $53.93 \%$ \\
\hline Intuitive & 18 & $47.37 \%$ & 23 & $45.10 \%$ & 41 & $46.07 \%$ \\
\hline
\end{tabular}

\section{Reasoning dimension distribution by gender}

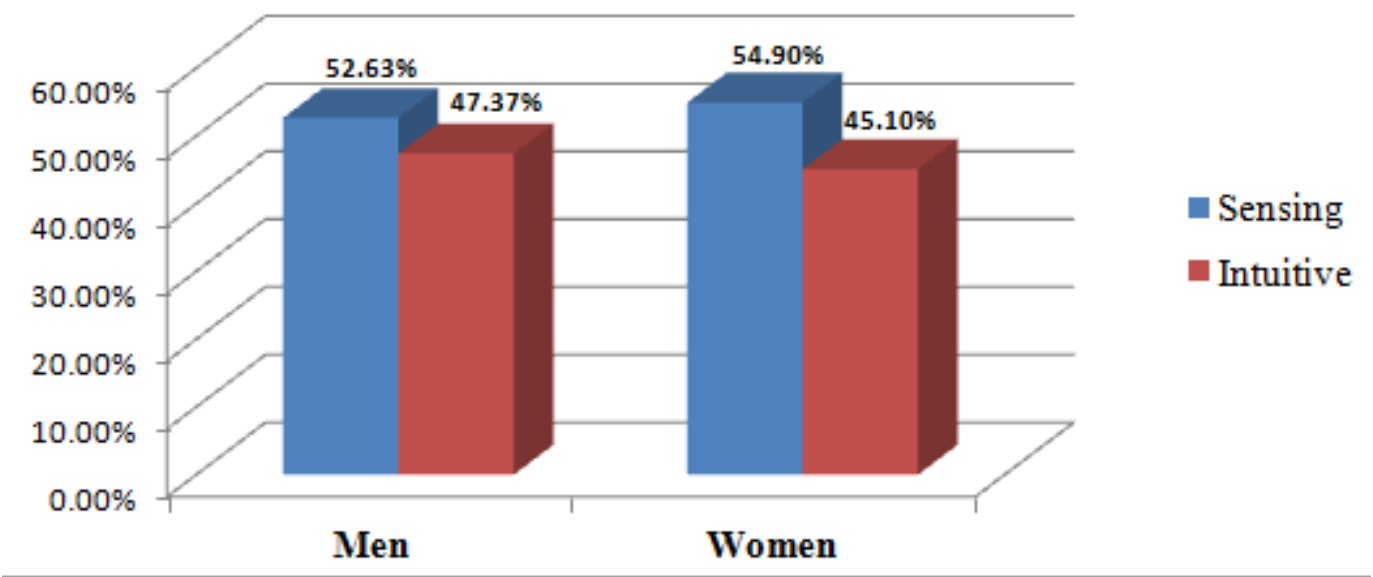

Fig. 12. Graph of reasoning dimension distribution by gender.

Regarding the reasoning dimension, we see that men and women get almost the same percentage for the sensing style (52\% of men and $54 \%$ of women), as well as the intuitive style ( $47 \%$ of men and $45 \%$ of women).

- Sensory dimension 
Table 10. Sensory Dimension Distribution by Gender

\begin{tabular}{|l|r|r|r|r|r|r|}
\cline { 2 - 7 } \multicolumn{1}{c|}{} & \multicolumn{2}{c|}{ Men } & \multicolumn{2}{c|}{ Women } & \multicolumn{2}{c|}{ Total } \\
\cline { 2 - 7 } \multicolumn{1}{c|}{} & \multicolumn{1}{c|}{ Number } & Percentage & Number & Percentage & \multicolumn{1}{c|}{ Number } & \multicolumn{1}{c|}{ Percentage } \\
\hline Visual & 21 & $55.26 \%$ & 26 & $50.98 \%$ & 47 & $52.81 \%$ \\
\hline Verbal & 17 & $44.74 \%$ & 25 & $49.02 \%$ & 42 & $47.19 \%$ \\
\hline
\end{tabular}

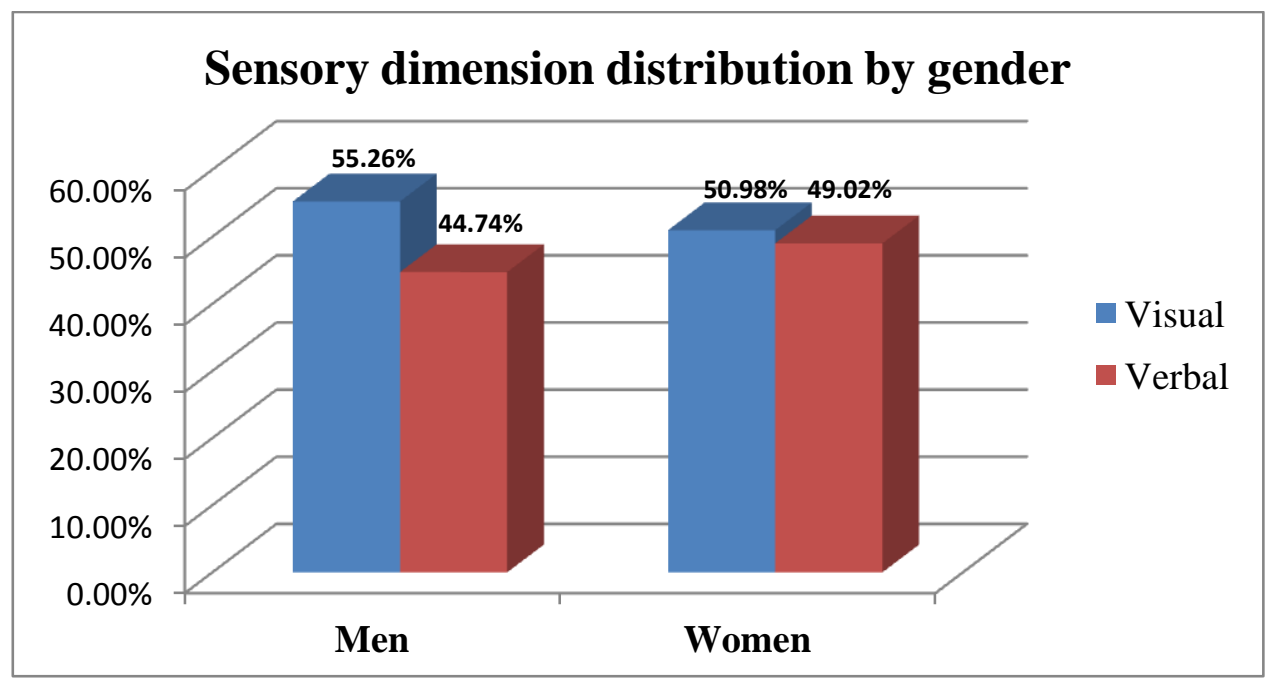

Fig. 13. Graph of sensory dimension distribution by gender

The statistics of the sensory dimension distribution show that men are more visual than women by $55 \%$ to $50 \%$. This suggests that the men in our sample prefer images, graphics, animations and videos as tools for presenting information. However, the verbal style is more pronounced in women than in men by $49 \%$ against $44 \%$.

- $\quad$ Progression dimension

Table 11. Progression dimension distribution by gender

\begin{tabular}{|l|r|r|r|r|r|r|}
\cline { 2 - 7 } \multicolumn{1}{c|}{} & \multicolumn{2}{c|}{ Men } & \multicolumn{2}{c|}{ Women } & \multicolumn{2}{c|}{ Total } \\
\cline { 2 - 7 } \multicolumn{1}{c|}{} & \multicolumn{2}{c|}{ Number } & Percentage & Number & Percentage & \multicolumn{2}{c|}{ Number } & Percentage \\
\hline Sequential & 15 & $39.47 \%$ & 17 & $33.33 \%$ & 32 & $35.96 \%$ \\
\hline Global & 23 & $60.53 \%$ & 34 & $66.67 \%$ & 57 & $64.04 \%$ \\
\hline
\end{tabular}

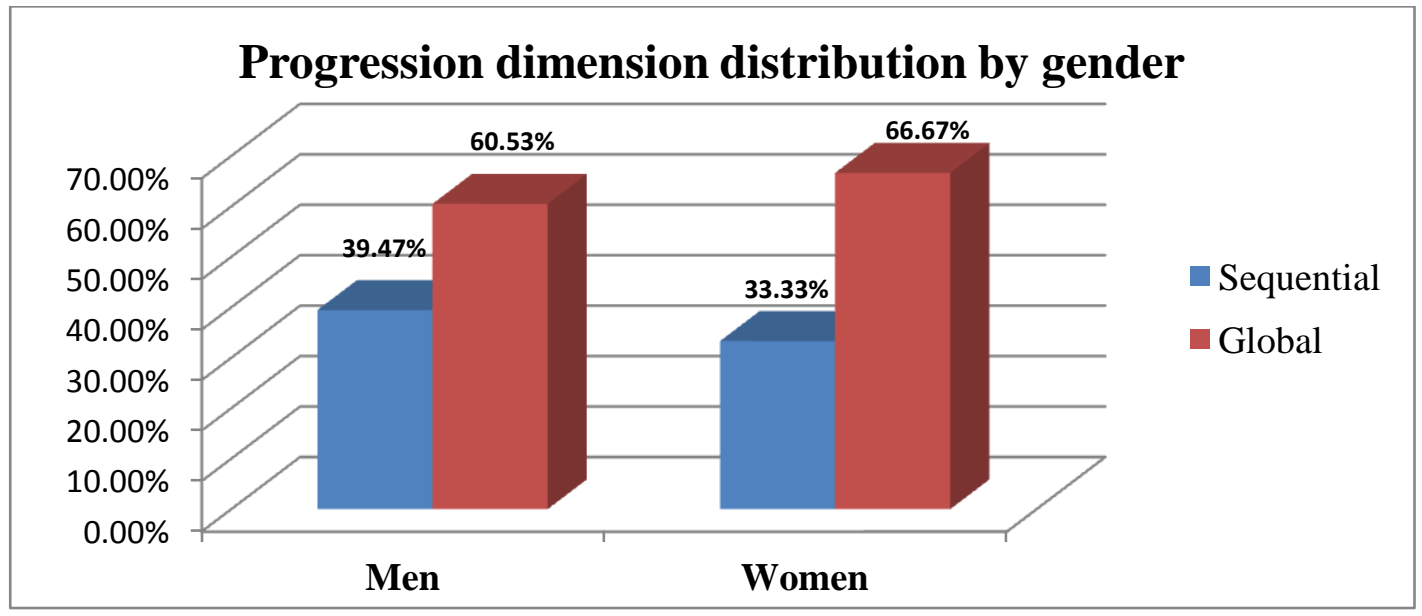

Fig. 14. Graph of progression dimension distribution by gender. 
Regarding the progression dimension, men are more sequential than women by $39 \%$ against $33 \%$, while the percentage of women who prefer a global vision in the educational sequence is higher than men by $66 \%$ against $60 \%$.

\section{Discussion and Conclusions}

This study has led to several scientific results:

First, the experiment allowed us to test the performance of the adaptive Learning Management System Manhali, and its usability for the management of distance learning.

Then, regarding learners' behavior and learning style, we confirmed two hypotheses:

On the one hand, in e-Learning, there is a relationship between the behavior of a learner and their academic performance. The comparison of behavioral scores compounded with the marks given by the teachers, shows that learners classified as "B" Grade get good grades in classroom training compared to students who achieved a lower behavioral grade like $\mathrm{C}, \mathrm{D}$ or $\mathrm{E}$.

On the other hand, there is a relationship between the gender of the learner and their learning style. Studies show that men and women tend to differ in terms of motivation, self-concept, abilities, achievement and performance [15]. Males and females have also evolved different behavioral strategies, and learning strategies [16]. Females tend to be read-write or auditory learners, and males tend to be visual and kinesthetic learners [17]. Females also tend to prefer cooperation, note-taking, and task mastery, whereas men are more likely to prefer competition, challenge and independent work, and avoid note-taking as a study strategy $[18,19]$. Therefore, gender differences in learning preferences do not mean that all female students learn one way and all male students learn another way, but it does reflect significant differences in the ways females and males learn [20].

Let us now analyze the results of the distribution of learning styles by gender in relation to these prominent scientific theories:

Concerning Kolb's learning styles; we found that the percentage of women who have an "Accommodating/Converging" style is higher than men by $56 \%$ against $52 \%$, knowing that this category includes students who prefer handling, task execution and implementation of activities.

Regarding Felder's learning styles; we noticed that most women have an active style while men in our sample employ the reflective style -recall that a reflective learner often prefers to work alone or with one regular partner, however, an active learner tends to like group work. With regards to the sensory dimension (visual/verbal), we notice that men are more visual (pictures, diagrams, films, demonstrations...) than women by $55 \%$ against $50 \%$, however, the percentage of women who prefer a verbal style (text and audio) is higher than men by $49 \%$ against $44 \%$.

These results confirm the studies we have cited about the difference between men and women regarding learning strategies and working methods.

This work shows also that 29 students have never logged in to the platform; it means that $24.58 \%$ of the sample are not interested in e-learning as a complement of face-to-face learning (Blended learning). So, the behavior and the learning style are not the only factors to a success e-learning training, this can take us after that to work on a third factor: motivation.

\section{References}

[1] Haddioui, E. I., \& Khaldi, M. (2012a). Learner behavior analysis on an online learning platform. International Journal of Emerging Technologies in Learning, 7(2), 22-25.

[2] Felder, R., \& Silverman, L. (1988). Learning and teaching styles in engineering education. Engr. Education, 78(7), 674-681. 
[3] Kolb, D. (1984). Experiential learning: Experience as the source of learning and development. Englewood Cliffs, NJ: Prentice Hall.

[4] Popescu, E. (2008). Thesis: Dynamic adaptive hypermedia systems for e-learning. University of Craiova, Romania. November 2008.

[5] Beshuizen, J. J., \& Stoutjesdijk, E. T. (1999). Study strategies in a computer assisted study environment. Learning and Instruction, 9, 281-301.

[6] Keefe, J. (1979). Learning style: An overview. NASSP's Student Learning Styles: Diagnosing and Prescribing Programs, 1-17.

[7] Riding, R. J., \& Rayner, S. (1998). Cognitive Styles and Learning Strategies: Understanding styLe Differences in Learning and Behaviour. David Fulton Publishers.

[8] James, W., \& Gardner, D. (1995). Learning styles: Implications for distance learning. New Directions for Adult and Continuing Education, 67.

[9] Gregorc, A. F. (1979). Learning/Teaching Styles: Potent Forces behind Them. Educational Leadership, 36 (4).

[10] Keefe, J., \& Ferrell, B. (1990). Developing a Defensible Learning Style Paradigm. Educational Leadership, $48(2)$.

[11] Piombo, C. (2007). Thesis: Modélisation probabiliste du style d'apprentissage et application à l'adaptation de contenus pédagogiques indexés par une ontologie. University of Toulouse, France. October 2007.

[12] Haddioui, E. I., \& Khaldi, M. (2012b). Learning style and behavior analysis: A study on the learning management system manhali. International Journal of Computer Applications, 56(4), 9-15.

[13] Felder, R. (1993). Reaching the second tier: Learning and teaching styles in college science education. J. College Science Teaching, 23(5), 286-290. 1993.

[14] Felder, R., \& Soloman, B. (2001). Index of learning styles questionnaire. Retrieved from website: http://www.engr.ncsu.edu/learningstyles/ilsweb.html

[15] Wigfield, A., Battle, A., Keller, B. L., \& Eccles, S. J. (2001). Sex differences in motivation, self-concept, career aspiration and career choice: Implications for cognitive development. Biology, Sociology and Behavior: The Development of Sex Differences in Cognition, 93-126.

[16] Cahill, L. (2006). Why sex matters for neuroscience. Nature Reviews Neuroscience, 2006.

[17] Geist, E. A., \& King, M. (2008). Different, not better: Gender differences in mathematics learning and achievement. Journal of Instructional Psychology, 35(1), 43-52.

[18] Cagla, A. I., \& Nimet, U. G. (2009). The influence of digit ratio on the gender difference in learning style preferences. Personality and Individual Differences Journal, 46, 424-427.

[19] Croson, R., \& Gneezy, U. (2009). Gender differences in preferences. Journal of Economic Literature, 47, 448-474.

[20] Sax, L. (2005). Why gender matters that parents and teachers need to know about the emerging science of sex differences. USA: Random House Inc.

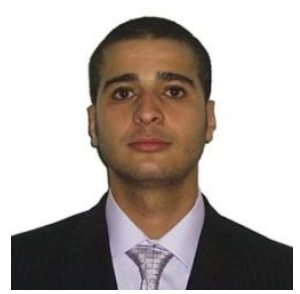

Ismail El Haddioui was born in Tetouan, Morocco, in 1985. He received his Ph.D. degree in computer science at Abdelmalek Essaadi University, Morocco in 2013. Now, he is an assistant professor in Superior School of Technology of Casablanca, Hassan II University. His research interests include e-Learning, Eye Tracking and psychology of learning. 


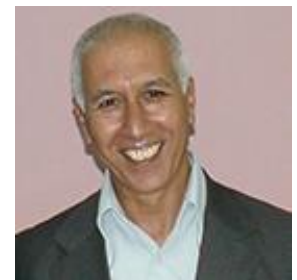

Mohamed Khaldi was born in Chefchaoun, Morocco, in 1959. He received his Ph.D. degree in pedagogy at Hassan II University, Morocco in 2001. Now, he is a professor of pedagogy in Abdelmalek Essaadi University. He works on pedagogy and e-Learning. 